\title{
Evaluating Well-being Among Dental Students Using the Warwick-Edinburgh Mental Well-being Scale and the Relationship Between Mental Well- being and Socio-demographic Findings
}

\author{
Warwick-Edinburgh Mental Iyi Oluş Ölç̧ği ile Diş Hekimliği \\ Öğrencilerinde lyi Olușun Değerlendirilmesi ve Mental lyi Oluş ile \\ Sosyo-demografik Bulgular Arasındaki Ilişki
}

(D) Mehtap Bilgin Çetin, (D) Yasemin Sezgin, (D) Seray Akıncı, (D) Nilgün Özlem Alptekin

Başkent University Faculty of Dentistry, Department of Periodontology, Ankara, Turkey

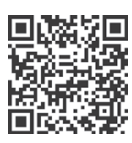

Keywords

Dental education, dental students, mental well-being, questionnaire, WarwickEdinburgh Mental Well-Being Scale

\section{Anahtar Kelimeler}

Diş hekimliği eğitimi, diş hekimliği öğrencileri, mental sağlık, anket, WarwickEdinburgh Mental İyi Oluş Ölçeği

Received/Geliş Tarihi : 04.09.2020

Accepted/Kabul Tarihi : 08.02.2021

doi:10.4274/meandros.galenos.2021.69783

Address for Correspondence/Yazışma Adresi: Mehtap Bilgin Çetin MD,

Başkent University Faculty of Dentistry, Department of Periodontology, Ankara, Turkey Phone : +90 5056344229

E-mail : mehtapblgn@yahoo.com

ORCID ID: orcid.org/0000-0003-3164-6886

(C) Meandros Medical and Dental Journal, Published by Galenos Publishing House.

This is article distributed under the terms of the Creative Commons Attribution NonCommercial 4.0

International Licence (CC BY-NC 4.0).

\section{Abstract}

Objective: The present study aimed to measure mental well-being among dental students using the Warwick-Edinburgh Mental Well-being Scale (WEMWBS) and to investigate factors affecting well-being.

Materials and Methods: Başkent University Faculty of Dentistry students were invited to participate in the study in 2019. The participants were asked to complete the WEMWBS and a questionnaire describing their demographic details, social background and lifestyle habits.

Results: A total of 268 dental students (68\% females) participated in the survey, with a response rate of $85 \%$. The overall WEMWBS score of the study population was 48.18 \pm 9.6 . Statistically significant differences in WEMWBS scores were detected between first- and fourth-year $(p<0.001)$ students and between fourth- and fifthyear students $(p<0.001)$. Male students $(p<0.001)$ whose first choice was to attend the school of dentistry $(p=0.024)$ and who pursued hobbies $(p=0.001)$ or regular sports activities $(p=0.001)$ had significantly higher WEMWBS scores than those who did not. Dental students' smoking status $(p=0.630)$, living accommodation $(p=0.71)$ or parents' education level did not affect WEMWBS scores significantly. Conclusion: The mental well-being of dental students was influenced by their year of study, gender, first choice of school and pursuit of hobbies or regular sports activities. Factors that may affect the mental well-being of students should be carefully considered, and strategies should be implemented to monitor and promote well-being during the students' academic career.

Öz

Amaç: Bu çalışmada, Warwick-Edinburgh Mental İyi Oluş Ölçeği (WEMioÖ) kullanılarak diş hekimliği öğrencilerinin mental iyi oluşunu ölçmek ve iyi oluşu etkileyen faktörleri incelemek amaçlanmıştır.

Gereç ve Yöntemler: Bu çalışmaya Başkent Üniversitesi Diş Hekimliği Fakültesi'nde öğrenim gören öğrenciler dahil edilmiştir. Katılımcılara WEMiOÖ ile demografik detaylar, sosyal geçmiş ve yaşam tarzı alışkanlıklarını içeren bir anket uygulanmıştır. 
Bulgular: Çalışmaya 268 (\%68 kadın) diş hekimliği öğrencisi katılmıştır. Çalışma popülasyonunun genel WEMioö skoru 48,18 olarak bulunmuştur. Birinci ve dördüncü sınıf öğrencileri $(p<0,001)$ ile dördüncü ve beşinci sınıf öğrencilerinin WEMioÖ skorları $(p<0,001)$ arasında istatistiksel olarak anlamlı farklılıklar tespit edilmemiştir. Erkek öğrencilerin $(p<0,001)$, ilk tercihleri diş hekimliği fakültesine gitmek olan $(p=0,024)$ ve hobileri $(p=0,001)$ veya düzenli spor alışkanlıkları olan $(p=0,001)$ öğrencilerin WEMioö skorları daha yüksek bulunmuştur. WEMiOÖ skorları açısından diş hekimliği öğrencilerinin sigara içme $(p=0,630)$, barınma $(p=0,71)$ veya ebeveynlerin öğrenim durumları açısından anlamlı bir farklılık bulunmamıştır.

Sonuç: Mevcut sonuçlar, diş hekimliği öğrencilerinin mental sağıklarııı fakültedeki öğrenim yılı, ilk tercihlerinin diş hekimliği fakültesi olması, cinsiyet, hobi veya düzenli spor alışkanlıklarının varlığından etkilendiğini göstermiştir. Öğrencilerin mental sağlıklarını etkileyebilecek faktörlerin iyi değerlendirilmesi ve akademik kariyerleri boyunca refahlarını izlemek ve geliştirmek için stratejilerin mevcut olması önemlidir.

\section{Introduction}

The significance of recent studies focused on positive mental health and its influence on our lives has elevated greatly. Positive mental health has been characterized as a condition that enables people to comprehend their capabilities including overcoming the everyday life pressure, being productive and participating in the society (1). In policy and academic literature, the term positive mental health is in accordance with the term mental wellbeing, in which both have impacts on psychological functioning in terms of hedonic and eudaemonic aspects. Personal understanding of happiness and life satisfaction constitute the core of hedonism, whereas psychological functioning and self-realization widely refer to eudaimonism (2).

Previous studies have shown a strong link between mental and physical health $(3,4)$. In addition, it was reported that individuals having elevated levels of mental well-being had higher creativity levels, improved immune systems, better relationships with other people; in addition to being more productive at work and living longer (5).

In order to determine the well-beings, either mental or psychological, there were widely accepted and commonly used appliances. Among those, Scale of Psychological Well-Being (6), the Satisfaction with Life Scale (7), PANAS Scale (8) and Short Depressionhappiness Scale (9) evaluated the mental well-being by addressing to either hedonic or eudaemonic perspectives, but not both. Therefore, a new scale, which assessed the entire concept including hedonic and eudaemonic perspectives, was needed to be proposed. For this reason, researchers in the United Kingdom (UK) introduced Warwick-Edinburgh Mental Well-Being Scale (WEMWBS) (10).
WEMWBS has been frequently used in studies as a convenient tool to score mental well-being $(11,12)$. This scale has been translated into numerous languages such as Norwegian, Swedish, Italian, Dutch, German, French and Spanish and has been validated (13-15). Validity and reliability studies of the Turkish version were performed in 2015 and it was concluded that the Turkish WEMWBS had a single factor structure and could be constituted as a valid and reliable research instrument in order to evaluate mental well-being (16).

Stressful occupations and work environments are both known to have negative influences on health, especially the mental health. It has been shown that university students suffer from psychological problems due to educational stress that are usually faced while trying to satisfy ascending demands from the university (17). This is particularly the case for students who study medical care fields since they have to cope with increased hours of work, tiring workload, and challenging theoretical education (18). In addition, dental students are required to obtain training in practical education which includes laboratory requirements in the preclinical years and clinical requirements in the clinical parts of their training. All of the aforementioned factors combine to cause a significant level of stress in dental students (19). Therefore, dental education is considered to be one of the most stressful health fields (20) and this led researchers to focus on examining the stress sources and psychological well-being among dental students in the last decades. In order to investigate the sources and levels of stress that these students experience, multiple researches have been performed in different dental schools globally. Surveys with the Dental Environment Stress (DES) questionnaire have been 
used in great amount of studies, which were also conducted with dental students and demonstrated that they have been suffering increased levels of stress during the ongoing training $(19,21)$. Although there are several studies in the literature that evaluate the mental well-being of dental students (22-24), few studies used WEMWBS $(25,26)$. Therefore, this study is conducted to measure the mental well-being of dental students by WEMWBS and investigate the factors that affect their well-beings.

\section{Materials and Methods}

This cross-sectional study was carried out by first to fifth year dental students of Başkent University. The study protocol was approved by Institutional Review Board and Ethics Committee of Başkent University (decision no: 19/97, date: 18.09.2019). This study was registered under the Clinical Trials protocol registration system (NCT04100928).

The survey was scheduled in a way that the assessment stage of the students would be independent. The participants were chosen among the students who attended a lecture together. By the end of the lecture, a researcher has informed the students about the aim of this voluntary survey and has also addressed the confidentiality issues, in which all identities would remain anonymous. The questionnaires were handed to the volunteered students. The questionnaire consisted of demographical details (age, gender, year of study), social background (parents' education levels, first choice for admission, living accommodation) and lifestyle habits (smoking status, presence of regular sports activities and hobbies). In addition, WEMWBS was applied to the participants of this study.

In a broad population of UK WEMWBS has been validated, where it was also introduced initially (10). In 2015, it has been translated into Turkish and validation process has been accomplished. The internal consistency coefficient and combined reliability coefficient of the scale were determined as 0.92 (16). Total of 14 features that address hedonic, as well as eudaemonic perspectives of mental health were found in this self-administered scale. These perspectives included positive influences such as optimism, happiness, enjoyment, relaxation; accomplishment of interpersonal contacts and positive actions such as energy, clear mind. Participants were asked to mark the boxes that describe 5-point Likert scale (none of the time, rarely, some of the time, often, all of the time) based on their situations of past 2 weeks. Giving a score of 1 to 5 , the minimum of 14 and maximum of 70 points could be acquired from the Likert scale. The features were scored in positive manner and all of them had equal weights. The overall grade was calculated by adding all scores. Thus, higher score represented elevated level of mental well-being and vice versa. The demographical, socio-economical and smoking information of participants were also obtained.

\section{Statistical Analysis}

Data analysis was performed using SPSS for Windows, version 21 (SPSS Inc., Chicago, IL, United States). The data were analyzed for normality of distribution with Shapiro-Wilk test. Mann-Whitney $\mathrm{U}$ test was used for two group comparisons (gender, sport habit, presence of a hobby and whether the dentistry was their first choice). The Kruskal-Wallis test was used to compare more than two independent groups (overall WEMWBS scores in the five years of the dental program, living accommodation, education level of the parents, smoking status). When the p-value of the Kruskal-Wallis test was statistically significant, Bonferroni adjusted Mann-Whitney $U$ test was used for multiple post-hoc comparisons. Cronbach's alpha coefficients were computed to determine the reliability of the WEMWBS.

\section{Results}

Table 1 provides the detailed demographics of study population. A total of 268 dental students $(68 \%$ female) participated, with a response rate of $85 \%$; among them 183 (68\%) were female, while 85 (32\%) were male students. The age range was 18 to 25 years with mean age of $21.11 \pm 1.77$ years. The majority of the students (89.1\%) reported that dentistry was their first career choice. $48 \%$ of participants were living with their parents and $186(69.4 \%)$ students were non-smokers.

The overall WEMWBS scores and WEMWBS scores according to the year of study are summarized in Table 2. Based on the reliability analysis, the internal consistency (Cronbach's alpha) was 0.90 for the WEMWBS. The overall WEMWBS score of the study 


\begin{tabular}{|c|c|c|c|c|c|}
\hline \multirow{2}{*}{ Year of study } & \multirow{2}{*}{$\mathbf{n}$} & \multicolumn{2}{|c|}{ Gender } & \multirow{2}{*}{ Response rate by year (\%) } & \multirow{2}{*}{ Mean age } \\
\hline & & Female & Male & & \\
\hline 1 & 69 & 41 & 28 & 66.3 & 19.45 \\
\hline 2 & 63 & 44 & 19 & 94 & 20.48 \\
\hline 3 & 56 & 46 & 10 & 93.3 & 21.37 \\
\hline 4 & 35 & 22 & 13 & 100 & 22.35 \\
\hline 5 & 45 & 30 & 15 & 95.7 & 23.27 \\
\hline Total & \begin{tabular}{|l|}
268 \\
\end{tabular} & 183 & 85 & 85 & 21.11 \\
\hline
\end{tabular}

population was $48.18 \pm 9.6$. When the WEMWBS scores were analyzed by the year of the study, statistically significant difference was detected. The WEMWBS scores were highest in first year students (51.1 \pm 7.21$)$ and lowest in $4^{\text {th }}$ year students $(42.47 \pm 10.33)$. The difference was statistically significant between year 1 and year $4(p<0.001)$; along with year 4 and year 5 $(p<0.001)$.

Table 3 illustrates the role of demographical details, social background and lifestyle habits on overall WEMWBS scores. Statistically significant differences were observed when overall WEMWBS scores were compared by gender. Female dental students (46.4 \pm 9.4$)$ exhibited lower WEMWBS scores compared to their male (52.12) counterparts $(p<0.001)$. Dental students who reported that dentistry was their first career choice had higher WEMWBS scores $(p=0.024)$. This trend could also be observed in case of sports activities and presence of hobbies. Significantly higher WEMWBS scores were acquired among students who had hobbies (WEMWBS scores: $50.11 \pm 9.8$ versus $46.1 \pm 8.9, p<0.001$ ) or regular sports activities (WEMWBS scores: $49.9 \pm 9.4$ versus $46.6 \pm 9.6$, $p=0.01$ ). WEMWBS scores did not differ regarding to dental students' smoking status $(p=0.630)$, living accommodation $(p=0.710)$, or educational levels of the parents $(p=0.522$ and 0.669 for mothers and fathers, respectively).

\section{Discussion}

The aim of this study was to assess the mental wellbeing of dental students using WEMWBS. In addition, factors with potential influences on dental student's well-being were investigated in the present study. Our research included 268 dental students and the overall WEMWBS score of this population was $48.18 \pm 9.6$. In this study, we obtained a response rate of $85 \%$ from the students enrolled. Moreover, Cronbach's alpha coefficients for WEMWBS demonstrated very high reliability. Thus, we acknowledge that our findings clearly represent the ongoing conditions of dental students of Başkent University Faculty of Dentistry.

There are many studies in the literature evaluating mental well-being with different scales $(10,22,23,27,28)$. Among these, WEMWBS was firstly developed by Tennant et al. (10) in 2007 and it was validated on a student and representative population sample. The median score was found to be 50 in the student sample and 51 in the population sample. Similarly, WEMWBS was used to assess mental wellbeing in Northern Ireland by analyzing the responses from 3,355 people of the general population, aged 16 years and over. Parallel with the results of Tennant et al. (10), the overall median score for the WEMWBS in this sample was 50 (29). In a recent research mental well-being in Denmark was measured and crosscultural comparison was made through four European settings. The results of this study manifested that mean scores were $52.2 \pm 8.7$ in Denmark. When a comparison was made through four European settings, the highest overall mental well-being scores were reported to be that of Catalonia (58.1), which was then followed by Denmark, Iceland and England (49.8) (12). A cross-sectional survey that was performed on doctors, nurses, physiotherapists, pharmacists and dentists to measure their mental well-being has demonstrated that the mean score of this population was $48.1 \pm 9.4$, which was comparable with the present study (30). 


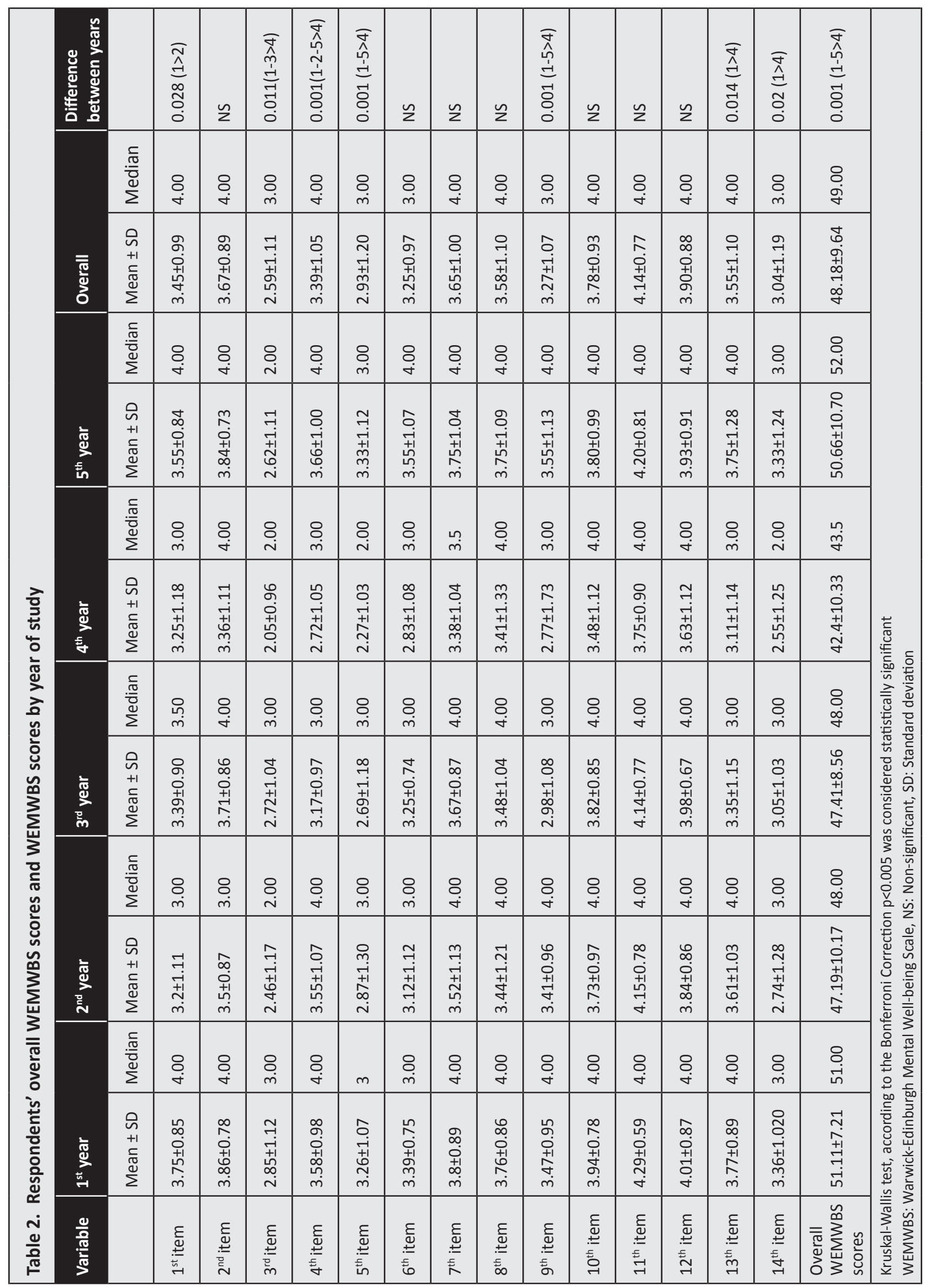




\begin{tabular}{|c|c|c|c|c|}
\hline \multirow{2}{*}{ Variables } & \multirow{2}{*}{$\mathbf{N}(\%)$} & \multicolumn{2}{|c|}{ Overall WEMWBS score } & \multirow{2}{*}{$p$-value } \\
\hline & & Mean \pm SD & Median & \\
\hline \multicolumn{5}{|l|}{ Gender } \\
\hline Male & $85(32)$ & $52.12 \pm 9.03$ & 49 & \multirow{2}{*}{$<0.001$} \\
\hline Female & $183(68)$ & $46.42 \pm 9.43$ & 47 & \\
\hline \multicolumn{5}{|l|}{ Living accommodation } \\
\hline With parents & $129(48)$ & $47.92 \pm 9.56$ & 49 & \multirow{4}{*}{0.710} \\
\hline At dorm & 51 (19) & $47.62 \pm 8.57$ & 48 & \\
\hline At home (alone) & $60(22)$ & $48.45 \pm 10.66$ & 51 & \\
\hline At home with room mate & $28(11)$ & $50.08 \pm 10.88$ & 48 & \\
\hline \multicolumn{5}{|l|}{ Dentistry first preference? } \\
\hline Yes & $239(89)$ & $48.7 \pm 9.31$ & 49 & \multirow{2}{*}{0.024} \\
\hline No & $29(11)$ & $43.8 \pm 11.36$ & 43 & \\
\hline \multicolumn{5}{|l|}{ Smoking status } \\
\hline Never smoked & $186(69.5)$ & $47.9 \pm 9.07$ & 48 & \multirow{4}{*}{0.630} \\
\hline$<1$ pack/day & $52(29.5)$ & $49.6 \pm 10.38$ & 51 & \\
\hline 1 pack/day & $28(10)$ & $48.1 \pm 11.10$ & 47 & \\
\hline$>1$ pack/day & $2(1)$ & $51 \pm 5.21$ & 51 & \\
\hline \multicolumn{5}{|c|}{ Education level of the mother } \\
\hline Primary school & $8(3)$ & $52.28 \pm 7.69$ & 53 & \multirow{5}{*}{0.522} \\
\hline Secondary school & $9(3)$ & $42.12 \pm 11.98$ & 44 & \\
\hline High school & $55(21)$ & $48.54 \pm 9.44$ & 48 & \\
\hline University & $147(55)$ & $47.9 \pm 10.18$ & 49 & \\
\hline Master/PhD & $49(18)$ & $48.77 \pm 7.97$ & 48 & \\
\hline \multicolumn{5}{|l|}{ Education level of the father } \\
\hline Primary school & $6(2)$ & $49 \pm 10.67$ & 47 & \multirow{5}{*}{0.669} \\
\hline Secondary school & $10(4)$ & $42.33 \pm 12.05$ & 45 & \\
\hline High school & $32(12)$ & $48.78 \pm 9.51$ & 48 & \\
\hline University & $142(53)$ & $48.08 \pm 9.78$ & 49 & \\
\hline Master/PhD & 78 (29) & $48.6 \pm 9.29$ & 49 & \\
\hline \multicolumn{5}{|c|}{ Presence of regular sport activity } \\
\hline Yes & $125(47)$ & $49.9 \pm 9.40$ & 51 & \multirow{2}{*}{0.001} \\
\hline No & $143(53)$ & $46.6 \pm 9.63$ & 47 & \\
\hline \multicolumn{5}{|l|}{ Having a hobby? } \\
\hline Yes & $139(52)$ & $50.11 \pm 9.85$ & 51 & \multirow{2}{*}{$<0.001$} \\
\hline No & $129(48)$ & $46.1 \pm 8.99$ & 47 & \\
\hline
\end{tabular}


These scores were lower than the scores obtained in general population surveys in the UK, Scotland, Northern Ireland, and Denmark $(10,12,29)$ and were in agreement with the previous studies showing worse psychological well-beings in medical students and higher levels of anxiety in dental students compared to general populations (31-33). Regarding the comparison of well-being scores with previous studies, it should be kept in mind that there were some minor varieties between the studies. Obtaining lower values could be explained by the work environments of the health care professions and also dental education programs which are known to be highly demanding and stressful.

Previous studies did not determined a standardized cut-off scores for the WEMWBS and it was reported that the average population mean was around 51 based on the study results which were conducted on different countries $(10,12,29)$. Present finding might seem to be lower than the previously reported average population mean. This difference may arise from the fact that subjective wellbeing varies across cultures (34). Therefore, we should be extremely cautious when using cut-off points for the classification and only nation-specific cut-off points should be employed.

Few studies exist in the literature that assessed the mental well-being of dental students with WEMWBS $(25,26)$. Lewis and Cardwell (25) compared the prevalence of mental well-being among veterinary medicine, medicine, dentistry and pharmacy students. They found that the mean score of the dental students was 45.41 . The overall WEMWBS score of the current study population is in line with the findings of Lewis and Cardwell (25). Other study which was conducted by Knipe et al. (26) was performed on medical, dentistry and veterinary students. The prevalence of mental health appeared to be higher in the first few years of college and decreased as students remained in education among medical and veterinary science students, although this pattern was not evident in dental students. Similarly, in this study, it was found that dental students exhibited a worse mental wellbeing in their last years.

When mean WEMWBS scores of each grade were compared, it was determined that the fourth-year students had the lowest $(42.47 \pm 10.33)$, whereas the first-year students had the highest $(51.11 \pm 7.21)$
WEMWBS scores. The differences between year 1 and 4 , along with year 4 and 5 were statistically significant. The fourth year of dental education is highly demanding because in addition to their theoretical trainings, dental students also need to obtain clinical training, which includes enrolling patients, taking care of them, executing permanent dental treatments, as well as pursuing clinical requirements and taking tests (19). Low WEMWBS scores in fourth-year students may be attributed to the accumulation of all aforementioned factors. Five-year students presented WEMWBS scores which were closed to the first-year scores and this score was significantly higher compared to fourth-year student's values. This variation in WEMWBS scores could be explained by the fact that the students were accustomed to both theoretical and clinical requirements. In addition, they were used to perform dental treatments after the first year of their clinical trainings; this might have reduced their anxiety about the career and increase their self-confidence which results in promoting their well-beings. However, this finding is in contrast with that of previous studies which reported higher level of stress in senior students than their younger peers. They suggested that the coursework becomes more difficult with each passing year. This difference could be explained by the factors specific to the participant population used in the studies or by the difference of the curricula between the universities (21,35-37).

While investigating the factors that may affect wellbeing, the present study found that male students' well-being scores were significantly higher than that of females. This finding was in accordance with previous studies $(21,38,39)$ and suggests that male students' overall well-being status was better than females. On the other hand, first choice for admission was previously reported as an important demographic variable and the studies clarify that the students, who could not achieve their initial career preferences, but ended up in dental school had lower well-beings $(21,38,40,41)$. In accordance with previous studies, our research has also proved that students who reported that dentistry was their first career choice had significantly higher WEMWBS scores. Students who have hobbies or regular sports activities yielded significantly higher WEMWBS scores. Presence of a hobby or regular sports activity promote good human relationships and values. Therefore, having hobbies 
or regular sports activities may well assist reducing the stress and promoting a sense of well-being of dental students as well (38). There were no significant differences in living accommodations, smoking status and parents' education levels in terms of the overall WEMWBS scores. There were contradictory findings in the literature about the effects of these factors on well-being. Number of studies reported a significant association of well-being with some of these factors $(39,42)$ whereas the others did not $(38)$. This difference could be explained by the varieties between the studies such as different social, economic and cultural characteristics of the study populations.

Dental students' mental well-being was explored in a limited number of studies by analyzing both feelings and functional perspectives of mental well-being. Thus, current study contributes to the literature in this field. However, the results of this study should be interpreted with caution since the cross-sectional design of our study, number of the participants and involving of students from private institution present limitations.

\section{Conclusion}

Present study adds significant contribution to the relevant literature by assessing dental students' wellbeings using WEMWBS, which includes both hedonic and eudaemonic dimensions. The mental well-beings of dental students were influenced by gender, first choice for admission, year of study, having hobbies or regular sports activities. Taken these results together, the factors that might affect the mental well-beings of the students should be considered and strategies should be in place to monitor and promote their well-beings during their academic careers. However, the results of the present study may not represent students' well-being in other dental schools. It would be of interest to compare well-beings of the present dental students to other faculty students and general populations. In addition, further research with prospective design involving a cohort of students over five years academic periods is recommended to monitor the mental well-beings of dental students' more objectively.

\section{Ethics}

Ethics Committee Approval: The study protocol was approved by Institutional Review Board and
Ethics Committee of Başkent University (decision no: 19/97, date: 18.09.2019).

Informed Consent: This cross-sectional study was carried out by first to fifth year dental students of Başkent University.

Peer-review: Externally and internally peerreviewed.

\section{Authorship Contributions}

Concept: M.B.Ç., Y.S., Design: N.Ö.A., S.A., Supervision: M.B.Ç., Y.S., S.A., N.Ö.A., Fundings: M.B.Ç., Y.S., S.A., N.Ö.A., Materials: S.A., Data Collection or Processing: S.A., Analysis or Interpretation: N.Ö.A., Literature Search: Y.S., M.B.Ç., Writing: Y.S., M.B.Ç., Critical Review: M.B.Ç. Y.S., S.A., N.Ö.A.

Conflict of Interest: No conflict of interest was declared by the authors.

Financial Disclosure: Başkent University Research Fund supported this research (D-KA19/28).

\section{References}

1. World Health Organisation:Promoting Mental Health; Concepts emerging evidence and practice. World Health Organisation 2004; p. 1-67.

2. Ryan RM, Deci EL. On happiness and human potentials: a review of research on hedonic and eudaimonic well-being. Annu Rev Psychol 2001; 52: 141-66.

3. Surtees PG, Wainwright NW, Luben RN, Wareham NJ, Bingham SA, Khaw KT. Psychological distress, major depressive disorder, and risk of stroke. Neurology 2008; 70: 788-94.

4. Ohrnberger J, Fichera E, Sutton M. The relationship between physical and mental health: A mediation analysis. Soc Sci Med 2017; 195: 42-9.

5. Lyubomirsky S, King L, Diener E. The benefits of frequent positive affect: does happiness lead to success? Psychol Bull 2005; 131: 803-55.

6. Ryff $\mathrm{CD}$, Keyes CL. The structure of psychological well-being revisited. J Pers Soc Psychol 1995; 69: 719-27.

7. Diener E, Emmons RA, Larsen RJ, Griffin S. The Satisfaction With Life Scale. J Pers Assess 1985; 49: 71-5.

8. Watson D, Clark LA, Tellegen A. Development and validation of brief measures of positive and negative affect: the PANAS scales. J Pers Soc Psychol 1988; 54: 1063-70.

9. Joseph S, Linley PA, Harwood J, Lewis CA, McCollam P. Rapid assessment of well-being: The Short Depression-Happiness Scale (SDHS). Psychol Psychother 2004; 77: 463-78.

10. Tennant R, Hiller L, Fishwick R, Platt $S$, Joseph $S$, Weich $S$, et al. The Warwick-Edinburgh Mental Well-being Scale (WEMWBS): development and UK validation. Health Qual Life Outcomes 2007; 5: 63.

11. Stewart-Brown S, Samaraweera PC, Taggart F, Kandala NB, Stranges S. Socioeconomic gradients and mental health: implications for public health. Br J Psychiatry 2015; 206: 461-5. 
12. Koushede V, Lasgaard M, Hinrichsen C, Meilstrup C, Nielsen $\mathrm{L}$, Rayce SB, et al. Measuring mental well-being in Denmark: Validation of the original and short version of the WarwickEdinburgh mental well-being scale (WEMWBS and SWEMWBS) and cross-cultural comparison across four European settings. Psychiatry Res 2019; 271: 502-9.

13. Castellví $P$, Forero CG, Codony $M$, Vilagut $G$, Brugulat $P$, Medina $A$, et al. The Spanish version of the Warwick-Edinburgh mental well-being scale (WEMWBS) is valid for use in the general population. Qual Life Res 2014; 23: 857-68.

14. Haver A, Akerjordet K, Caputi P, Furunes T, Magee C. Measuring mental well-being: A validation of the Short Warwick-Edinburgh Mental Well-Being Scale in Norwegian and Swedish. Scand J Public Health 2015; 43: 721-7.

15. Smith ORF, Alves DE, Knapstad M, Haug E, Aarø LE. Measuring mental well-being in Norway: validation of the WarwickEdinburgh Mental Well-being Scale (WEMWBS). BMC Psychiatry 2017; 17: 182.

16. Keldal G. Turkish Version of the Warwick-Edinburgh Mental Well-Being Scale: A validity and reliability study. The Journal of Happiness \& Well-Being 2015; 3: 103-15.

17. Tosevski DL, Milovancevic MP, Gajic SD. Personality and psychopathology of university students. Curr Opin Psychiatry 2010; 23: 48-52.

18. Birks $\mathrm{Y}, \mathrm{McKendree} \mathrm{J}$, Watt I. Emotional intelligence and perceived stress in healthcare students: a multi-institutional, multi-professional survey. BMC Med Educ 2009; 9: 61.

19. Elani HW, Allison PJ, Kumar RA, Mancini L, Lambrou A, Bedos C. A systematic review of stress in dental students. J Dent Educ 2014; 78: 226-42.

20. Cooper CL, Watts J, Kelly M. Job satisfaction, mental health, and job stressors among general dental practitioners in the UK. $\mathrm{Br}$ Dent J 1987; 162: 77-81.

21. Alzahem AM, van der Molen HT, Alaujan AH, Schmidt HG, Zamakhshary $\mathrm{MH}$. Stress amongst dental students: a systematic review. Eur J Dent Educ 2011; 15: 8-18.

22. Mahmud A. Mental health at dental school. Br Dent J 2020; 228: 3.

23. Lerman AR, Yamamoto KK, Taylor GW, Saeed SG. High depressive symptom prevalence in dental students associated with lifestyle and well-being characteristics. J Dent Educ 2020; 84: 771-80.

24. Fountain AC, Roberts EP, Schuster G, Breitmeyer AM, Stein AB. Dental Faculty, Student, and Alumni Perceptions of Happiness and Life Satisfaction in Dental School: Foundations for Resilience and Well-Being. J Dent Educ 2020; 84: 336-42.

25. Lewis EG, Cardwell JM. A comparative study of mental health and wellbeing among UK students on professional degree programmes. Journal of Further and Higher Education 2019; 43: 1226-38.

26. Knipe D, Maughan C, Gilbert J, Dymock D, Moran P, Gunnell D. Mental health in medical, dentistry and veterinary students: cross-sectional online survey. BJPsych Open 2018; 4: 441-6.
27. Wimberly CE, Rajapakse H, Park LP, Price A, Proeschold-Bell RJ, $\emptyset$ stbye T. Mental well-being in Sri Lankan medical students: a cross-sectional study. Psychol Health Med 2020: 1-14.

28. Pohjola V, Puolakka A, Kunttu K, Virtanen Jl. Association between dental fear, physical activity and physical and mental well-being among Finnish university students. Acta Odontol Scand 2020; 78: 45-51.

29. Lloyd K, Devine P. Psychometric properties of the WarwickEdinburgh Mental Well-being Scale (WEMWBS) in Northern Ireland. J Ment Health 2012; 21: 257-63.

30. Waqas A, Ahmad W, Haddad M, Taggart FM, Muhammad Z, Bukhari $\mathrm{MH}$, et al. Measuring the well-being of health care professionals in the Punjab: a psychometric evaluation of the Warwick-Edinburgh Mental Well-being Scale in a Pakistani population. PeerJ 2015; 3: 1264.

31. Pagnin D, de Queiroz V. Comparison of quality of life between medical students and young general populations. Educ Health (Abingdon) 2015; 28: 209-12.

32. Henning MA, Krägeloh CU, Hawken SJ, Zhao Y, Doherty I. The quality of life of medical students studying in New Zealand: a comparison with nonmedical students and a general population reference group. Teach Learn Med 2012; 24: 334-40.

33. Lloyd C, Musser LA. Psychiatric symptoms in dental students. J Nerv Ment Dis 1989; 177: 61-9.

34. Suh EM, Oishi S. Subjective Well-Being Across Cultures. Online Readings in Psychology and Culture 2002; 10: 1-11.

35. Babar MG, Hasan SS, Ooi YJ, Ahmed SI, Wong PS, Ahmad SF, et al. Perceived sources of stress among Malaysian dental students. Int J Med Educ 2015; 6: 56-61.

36. Naidu RS, Adams JS, Simeon D, Persad S. Sources of stress and psychological disturbance among dental students in the West Indies. J Dent Educ 2002; 66: 1021-30.

37. Amin WM, Al-Ali MH, Duaibis RB, Oweis T, Badran DH. Burnout among the clinical dental students in the jordanian universities. J Clin Med Res 2009; 1: 207-11.

38. Sugiura G, Shinada K, Kawaguchi Y. Psychological well-being and perceptions of stress amongst Japanese dental students. Eur J Dent Educ 2005; 9: 17-25.

39. Uraz A, Tocak YS, Yozgatligil C, Cetiner S, Bal B. Psychological well-being, health, and stress sources in Turkish dental students. J Dent Educ 2013; 77: 1345-55.

40. Acharya S. Factors affecting stress among Indian dental students. J Dent Educ 2003; 67: 1140-8.

41. Rajab LD. Perceived sources of stress among dental students at the University of Jordan. J Dent Educ 2001; 65: 232-41.

42. Humphris G, Blinkhorn A, Freeman R, Gorter R, Hoad-Reddick G, Murtomaa $\mathrm{H}$, et al. Psychological stress in undergraduate dental students: baseline results from seven European dental schools. Eur J Dent Educ 2002; 6: 22-9. 